\title{
The effect of droplet size on boundary migration of burning modes for autoignition of $\mathbf{n}$-heptane droplets
}

\author{
Wenyi Zhang ${ }^{1,2}$, Hengyi Zhou ${ }^{1,2}$, Yu Cheng Liu, ${ }^{1,2,3, *}$ \\ ${ }^{1}$ Center for Combustion Energy, Tsinghua University, Beijing 100084, China \\ ${ }^{2}$ Department of Energy and Power Engineering, Tsinghua University, Beijing 100084, China \\ ${ }^{3}$ Key Laboratory for Thermal Science and Power Engineering of Ministry of Education, \\ Tsinghua University, Beijing 100084, China
}

\begin{abstract}
The purpose of this study is to understand the effect of various diameter or ambient parameters on the autoignition and quasi-steady burning of $n$-heptane droplets. Spherically symmetric 1-D numerical simulations were conducted with various initial droplet diameter (50 $\mu \mathrm{m} \sim 2 \mathrm{~mm})$, ambient temperature $(500-1000 \mathrm{~K})$ and pressure $(1 \sim 20$ bar) to facilitate identification of ignition dynamics and intrinsic steady burning modes, including steady droplet cool flame, cool-to-hot transition and hot flame after single ignition, etc. Provided that different initial temperatures and pressures lead to a variety of ignition states, initial droplet diameters present further constraint to ignition behaviours through physical droplet life time. Such constraint sometimes can turn a two-stage ignition (longer life time) into a cool flame (shorter life time). Species with strong correlation with cool flame (KET (NC7KET24)) and hot flame $(\mathrm{OH})$ were used as identifiers for the dynamics of corresponding processes. FSR (Flame standoff ratio) for both cool and hot flame was found to be stabilized at $\mathrm{FSR}_{\mathrm{cool}} \approx 1.3$, and $\mathrm{FSR}_{\text {hot }} \approx 3.8$, respectively. The effect of droplet diameter is obvious when the droplet life time determines the termination of a heat release history. Such effect becomes less important for the mode boundaries primarily governed by fuel oxidation kinetics, i.e. between two-stage and single hot ignition (or between no ignition and single hot ignition).
\end{abstract}

Keywords: Droplet size; n-Heptane; Steady burning; Two-stage ignition

\section{Introduction}

Spray combustion has been the main configuration for releasing chemical heat from fuels inside engines. The complexity of spray combustion stems from its multi-phase and highly turbulent nature that has prohibited in detailed research in both experiments and numerical modelling. With relentless demand for modelling sub-grid phenomena in a spray combustion problem, many researchers shift their emphases on the droplet cloud or single droplet problems. Such problems allow precise validation by experimental data and more insightful understanding in terms of flame structure and consumption rates of particular fuels. Fuels of interest hence include the component that has been long considered for its importance for petroleum-derived fuels, and n-heptane is amongst the most important due to its role as primary reference fuel for gasoline. Therefore, droplet combustion for $n$-heptane has been investigated for many decades. Experiments carried out in microgravity promotes the spherically symmetric of droplet combustion and offer first-handed data for the comparison of the classical one-dimensional models. The earliest microgravity experiment on droplet combustion was carried out by Kumagai et al. [1] through igniting a fuel droplet during freefall. The data for droplet burning in quasi-steady state at standard ambient temperature was then used to validate the classical $D^{2}$ law. Other research created a high temperature environment in which the droplet is inserted during freefall to study autoignition behaviour of fuel droplets $[2,3,4,5]$. Conditions had covered droplet diameter $(0.65 \sim 0.75 \mathrm{~mm})$, pressure $(0.1 \sim 2 \mathrm{MPa})$ and temperature $(600 \mathrm{~K} \sim 1000 \mathrm{~K})$. There have also been experiments that utilize space resources, e.g. droplet ignition experiments in the Spacelab [6], and the flame extinguish 
experiment (FLEX) in the Space station [6,7]. Tanabe et al [2,3,4] established a regime diagram of droplet autoignition under different temperature and pressure, i.e. a T-P diagram, for various ignition states of $n$-heptane droplet. Such T-P diagram has been considered as the target for numerical simulation to legitimatize the use of transport and chemical kinetic models [8]. Recently phenomena of droplet cool flame documented through the FLEX experiments [9] have motivated investigation and modelling efforts in such diffusio-chemically coupled problem. Liu et al. [10] and Xu et al. [11] analysed the droplet burning experiments in FLEX. The cool flame appears after radiative extinction of hot flames. The evaporation rate of the droplet changes with initial diameter. Some researchers also noticed the effect of droplet diameter on the burning process in autoignition conditions. Moriue et al. [12] demonstrated that when droplets are between 1 and $100 \mu \mathrm{m}$, the ignition delay time exhibits a minimum with increasing droplet diameter. The shortest ignition delay time occurs when it is close to the droplet life time. Their results also show that droplet cool flame can exist for small droplets near engine spray conditions.

This paper attempts to unravel the effect of initial diameter on the boundary change of Temperature and Pressure (T-P) ignition state diagram through numerical simulation. Various droplet ignition modes and their inter-transitions with temperature, pressure and diameter are presented with preliminary analysis. The influence of diameter on the boundaries between different ignition modes of $n$-heptane droplet is shown and discussed using the T-P diagram.

\section{Numerical Methods}

In our numerical simulation, a droplet is suddenly exposed to a furnace environment with wellcontrolled pressure and temperature under microgravity. The droplet and flame are spherical burning at a constant pressure air condition. The gas phase products are not miscible in the liquid phase due to low temperature; negligible effect of supporting fibre; insignificant radiation effect and the thermophoresis and diffusio-phoresis effects. The following is the physical conservation equations of gas phase and liquid phase [13]:

$$
\begin{gathered}
\int_{r-}^{r+\frac{\partial(\rho h)}{\partial t}} r^{2} d r+\frac{\left.r^{2} \dot{r}\right|_{r} ^{r+}}{\left.\frac{1}{3} r^{3}\right|_{r-} ^{r+}} \int_{r-}^{r+} \rho h r^{2} d r+\left.h(\rho v-\rho \dot{r}) r^{2}\right|_{r-} ^{r+}=-\left.q r^{2}\right|_{r-} ^{r+}+\int_{r-}^{r+} \dot{Q} r^{2} d r \\
\int_{r-}^{r+\frac{\partial\left(\rho Y_{j}\right)}{\partial t}} r^{2} d r+\frac{\left.r^{2} \dot{r^{2}}\right|_{r-} ^{r+}}{\left.\frac{1}{3} r^{3}\right|_{r-} ^{r+}} \int_{r-}^{r+} \rho Y_{j} r^{2} d r+\left.Y_{j}(\rho v-\rho \dot{r}) r^{2}\right|_{r-} ^{r+}=-\left.\rho Y_{j} V_{j} r^{2}\right|_{r-} ^{r+}+\int_{r-}^{r+} \dot{\omega}_{j} r^{2} d r
\end{gathered}
$$

The outer gas boundary is 200 times of initial droplet radius and set as Dirichlet boundary, of which the initial conditions are identical to that of the gas phase. At the inner center of the droplet, no flux conditions are applied. At the droplet surface, the heat and mass conservations are described by the following equations [13]:

$$
\begin{aligned}
& h_{v a p}\left[Y_{d s, f u e l} \rho\left(v_{0}-\dot{r}\right)+\rho Y_{j} V_{j}\right]_{+}=-\left.q\right|_{-} ^{+} \\
& \left.Y_{j}(\rho v-\rho \dot{r})\right|_{-} ^{+}=-\left.\rho Y_{j} V_{j}\right|_{-} ^{+} \\
& \bar{\rho}_{l} \frac{d r_{0}}{d t}+\frac{r_{0}}{3} \frac{d \overline{\rho_{l}}}{d t}=-\rho_{g}\left(v_{0}-\frac{d r_{0}}{d t}\right)
\end{aligned}
$$

The Strang splitting method [14] is implemented for the decouple of chemical and physical terms. DVODE [15] is used to solve the decoupled stiff chemistry problems. The absolute and relative accuracy are set as $10^{-8}$. The finite volume method (FVM) with first order time implicit is implemented on solving other terms. A staggered grid system is used to reduce oscillation as suggested by a typical FVM setup. Based on the estimated diffusion time scale (i.e. $10^{-4} \mathrm{~s}$ ), 
the solution time step of $10^{-5} \mathrm{~s}$ is adopted. The criteria of convergence include both relative residual temperature and absolute residual value of the concentration being lower than $10^{-6}$. This work adopts 40 uniform cells in the liquid phase, 200 non-uniform cells in the gas phases. The cell number remains the same in the process of simulation. Due to migration of the droplet surface after each time step, the cell locations are re-determined to accommodate the liquidvapor boundary. The chemical kinetic model for $n$-heptane oxidation used in this study is from Yoo et al. [16], which contains 88 species and 387 reactions and verified for the low temperature conditions.

\section{Results and Discussion}

The simulation in the present study has been verified by experimental data of $\mathrm{n}$-heptane droplet with $0.65 \sim 0.75 \mathrm{~mm}$ diameter from Tanabe $[2,3,4]$ as shown by the prediction of $1^{\text {st }}$ and $2^{\text {nd }}$ induction time of the droplet in Figure 1. The first induction time, total induction time and droplet life time are defined as Cuoci et al [8]. Relatively good agreement between experimental data (symbols) and simulation (lines) suggests that the model captures the most important physics of the problem. Potential reason for the slight difference might have stemmed from the use of quartz filament $(0.15 \mathrm{~mm}$ in diameter) which further introduce heat loss from the droplets.

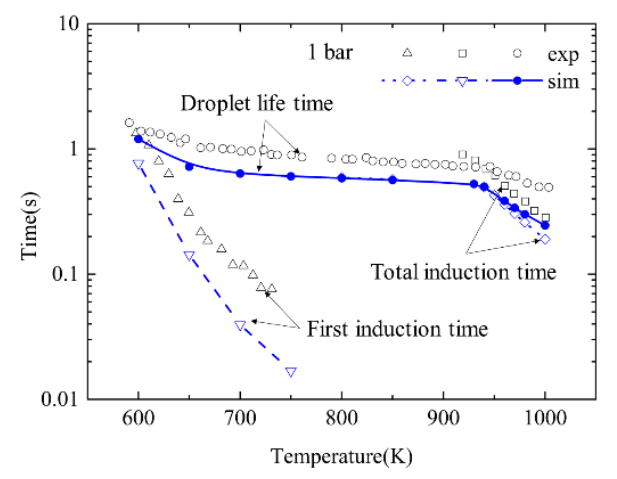

(a)

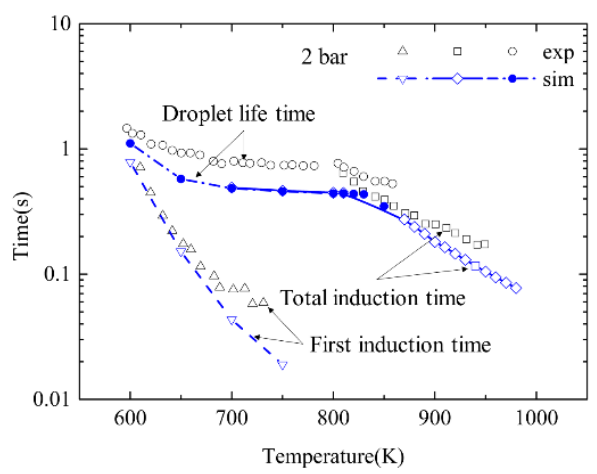

(b)

Figure 1. Droplet life time and induction times for $n$-heptane droplet: (a) 1 bar; (b) 2 bar. Experimental data are from Tanabe et al. [2,3,4]

Figure 2(a) demonstrates the temperature field in the burning process of a $0.75 \mathrm{~mm}$-heptane droplet. The blank field that shrinks with time simply indicates that the droplet radius decreases with time. The temperature rises at $0.045 \mathrm{~s}$ suggests that cool flame establishes around the droplet and keeps a flame temperature at about $800 \mathrm{~K}$. In contrast, Figure 2(b) shows a similar plot for a $2 \mathrm{~mm}$ droplet, where first stage ignition happens later (at $0.085 \mathrm{~s}$ ) comparing to a $0.75 \mathrm{~mm}$ droplet. Moreover, a second stage ignition at $0.85 \mathrm{~s}$ can be seen for a $2 \mathrm{~mm}$ droplet, forming a two-stage ignition history during its droplet life time. Such evident two-stage transition from steady cool flame to hot flame brings the maximum flame temperature from $800 \mathrm{~K}$ to $2000 \mathrm{~K}$ before droplet disappears at $1.54 \mathrm{~s}$. From the comparison of ignition histories of droplets with two different sizes, one can learn that only when the initial droplet diameter decreases to certain extent, the droplet life time becomes sufficiently short such that the second stage ignition can no longer exist. 


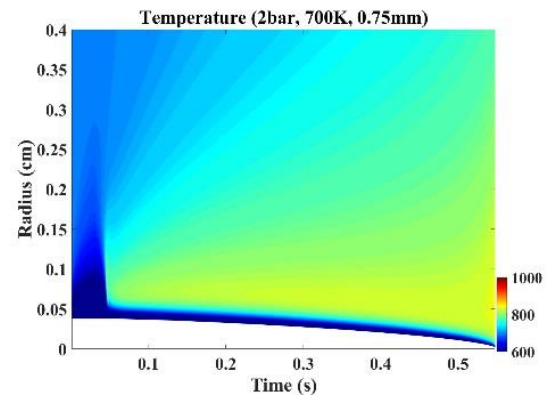

(a)

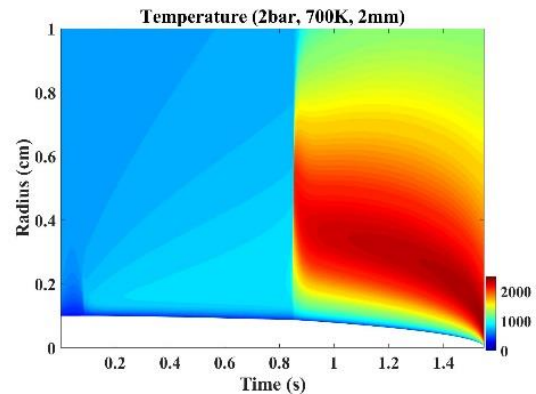

(b)

Figure 2. Temperature distribution of the gas phase around the droplet in the burning process. (a) Cool flame burning process under 2 bar and $700 \mathrm{~K}$ of $0.75 \mathrm{~mm}$-heptane droplet; Two-stage ignition process under 2 bar and $700 \mathrm{~K}$ of $2 \mathrm{~mm}$-heptane droplet.

Since the shorter life time limits the development of chemistry for small droplet, we hence investigate the ignition behaviour for much smaller droplets. Figure 3 shows one representative example ( 3 bar and $800 \mathrm{~K}$ ) of important intermediates ( $\mathrm{OH}$ and ketohydroperoxides, KET) and temperature during the burning of a $50 \mu \mathrm{m} n$-heptane droplet. As can be seen in Figure 3(c), the minimal temperature rises suggest that the cool flame induced by the hot ambient is relatively weak. However, the mass fractions of $\mathrm{OH}$ and KET shown in Figure 3(a) and 3(b), respectively, confirm the presence of droplet cool flame in its own structure. Note that such temperature variations surrounding a micron-sized droplet may not be detectable using the Michelson interferometry in the experiments of Tanabe et al. [3].

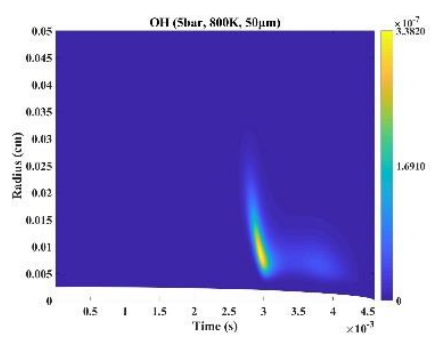

(a)

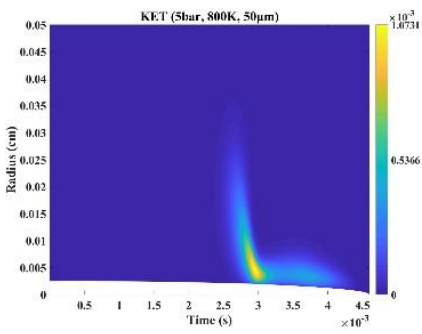

(b)

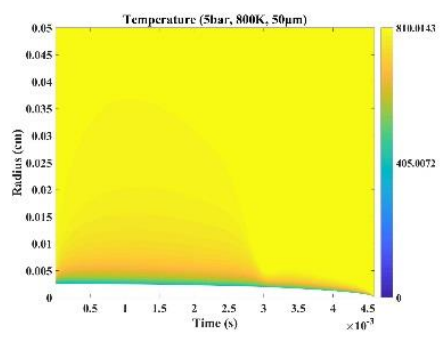

(c)

Figure 3. The $\mathrm{OH}$ and $\mathrm{KET}$ radical distribution around the $50 \mu \mathrm{m}$ droplet in the two-stage ignition process under 5 bar and $800 \mathrm{~K}$.

Similar to Figure 3, Figure 4 displays the evolution of $\mathrm{OH}, \mathrm{KET}$ and FSR (flame standoff ratio) for a droplet size (e.g. $2 \mathrm{~mm}$ ) that allows two-stage burning. As shown, successful ignition of cool flame can be evidently seen from the high KET zone (Figure 4(b)). Such cool flame zone is then followed by an abrupt appearance of high $\mathrm{OH}$ concentration (Figure 4(a)) suggesting that the burning enters the hot flame mode after the second stage ignition. Note that the $\mathrm{OH}$ is also an important intermediate for low temperature oxidation. However, comparing to the much stronger rate of production in hot flame, $\mathrm{OH}$ in the cool flame zone is less visible in the present fashion of presentation. Figure 4(c) shows the FSR (blue dashed line) and maximum temperature (red line) for the two-stage burning process. The FSR is defined as the instantaneous ratio of the radius of maximum heat release to the droplet radius. The maximum temperature shown here is extracted from Figure 2(b). It can be seen that before cool flame is actually ignited, the FSR only suggests an unsteady location where maximum heat release 
occurs, i.e. FSR can be as large as 3.0. After the droplet cool flame is established (at 0.085 s), FSR collapse to a constant around 1.3. Similar ignition process can also be seen for the second stage, expect that the quasi-steady FSR becomes around 3.8 for the hot flame.

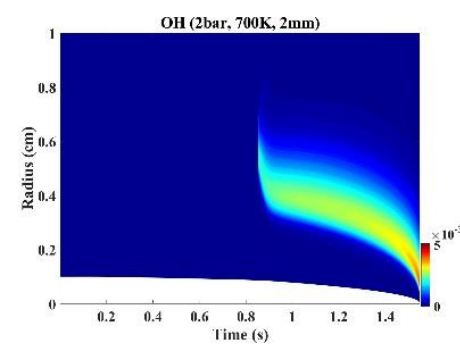

(a)

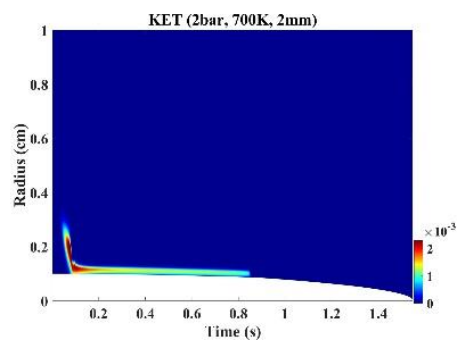

(b)

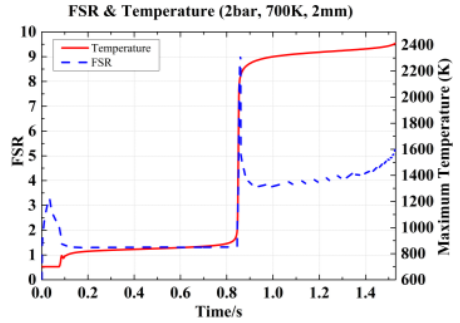

(c)

Figure 4. The two-stage ignition process of $2 \mathrm{~mm}$-heptane droplet under 2 bar and $700 \mathrm{~K}$, a) $\mathrm{OH}$ radical distribution; b) and KET radical distribution; c) the evolution of maximum temperature and FSR.

Figure 5 shows various ignition modes of a $0.75 \mathrm{~mm} \mathrm{n}$-heptane droplet on a T-P diagram. The black lines depict the boundaries of different modes from the experiments of Tanabe et al. [3] Ignition modes determined from our simulation are presented as symbols. As shown, the boundaries formed by the simulation results match well with the experimental T-P diagram from Tanabe et al. [3] The results shown in Figure 5 serve as a base case for our following discussion regarding the effect of droplet diameter. In particular, the boundaries between twostage and cool flame as well as between two-stage and the upper hot ignition are of the most interest since they represent very different droplet ignition modes that are intrinsic to the coupled chemical and physical process of droplet autoignition.

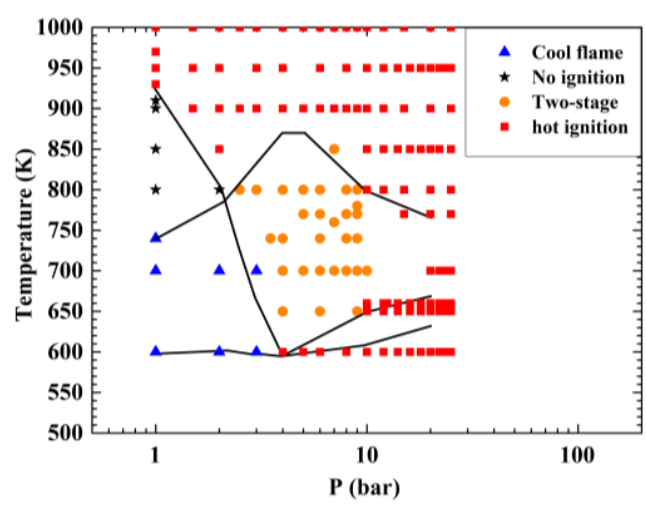

Figure 5. T-P diagram with the experimental lines [3] and points from numerical simulation from this work, that instead of ignition modes under certain temperature and pressure;

Figure $6(a)$ and (b) show the linear fit of the boundaries of interest from our simulation for three different droplet sizes, i.e. $0.2,0.75$, and $2.0 \mathrm{~mm}$. As shown by Figure $6(\mathrm{a})$, the boundary between cool flame and two-stage ignition migrates towards the lower T-P for larger droplets. Note that the same line also separates the no ignition region from single hot ignition region. Three linearly fitted boundaries in Figure 6 (a) exhibit similar slopes, suggesting they may be governed by the same chemistry. The migration of this boundary suggests that larger droplets promote longer droplet life time. Therefore for the same ignition heat release history, e.g. single stage hot ignition, the droplet life time $t_{d, \text { life }}$ terminates the history at certain point and form either no ignition (when $t_{i g}<t_{d, \text { life }}$ ) or successful single ignition $\left(t_{i g}<t_{d, \text { life }}\right.$ ). For the T-P 
condition that allows two-stage ignition, the droplet life time determines whether the burning mode is cool flame (when $t_{\text {ig, }, 1 s t}<t_{d}$,life $<t_{\text {ig,2nd }}$ ) or two-stage (when $t_{d, \text { life }}>t_{\text {ig,2nd }}$ ). On the contrary, Figure $6(\mathrm{~b})$ shows the other boundary between the two-stage ignition and single hot ignition. This boundary also extends to between cool flame and no ignition region. As shown, almost no noticeable difference can be found between the three lines regardless the different droplet sizes. The unchanged boundary in Figure $6(\mathrm{~b})$ is found to coincide with the "ceiling temperature curve' evaluated based on the equilibrium of mode switching reaction $\dot{\mathrm{R}}+\mathrm{O}_{2}$ $\leftrightarrow$ ROंO without effects from the transport process controlled by the characteristic length (i.e. droplet size).

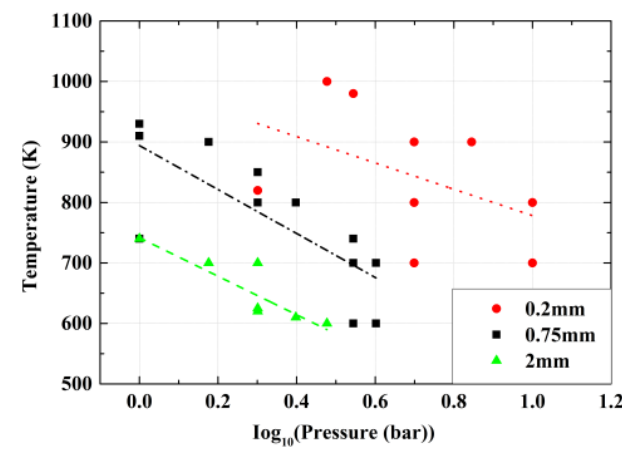

(a)

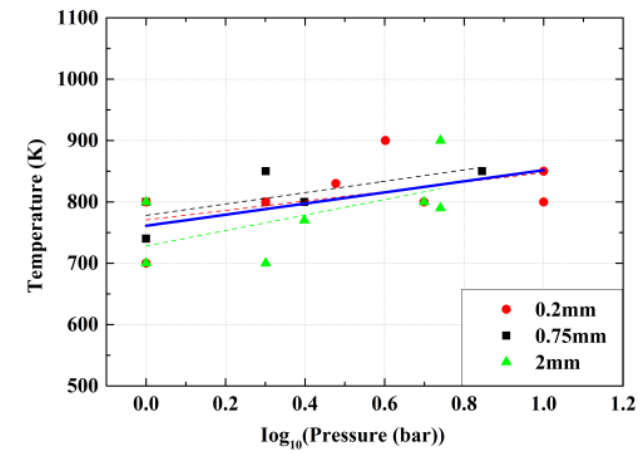

(b)

Figure 6. The linear fit boundaries under different initial diameters $(0.2 \mathrm{~mm}, 0.75 \mathrm{~mm}, 2 \mathrm{~mm})$, a) the boundary between the single cool flame region and two-stage ignition region, also the boundary between the no ignition and single hot ignition; b) the boundary between the cool flame and no ignition region, also the boundary between the two-stage ignition and single hot ignition.

\section{Conclusions}

The combustion processes of $n$-heptane droplet with different initial diameters $(50 \mu \mathrm{m} \sim 2 \mathrm{~mm})$ were successfully simulated in this research under the temperature range of $500 \sim 1000 \mathrm{~K}$ and pressure range of 1 20 bar. Intermediate species $(\mathrm{OH}$ and KET) reveal the onset of the cool and hot flame. From the simulation results, FSR stays constant around 1.3 during the first stage steady cool flame and 3.8 during the second stage steady hot flame. Various ignition modes have been identified for the numerical results and presented as symbols in the T-P diagram. The boundaries of burning modes for three different diameters were compared on the T-P diagram. The boundary between no ignition and cool flame (also between the twostage to single hot ignition modes) does not changes with initial droplet diameter, showing that it is primarily dictated by chemical kinetics of $n$-heptane oxidation. The other boundary of interest between the cool flame and two-stage modes (also between no ignition and single hot ignition) is mainly controlled by the droplet life time with respect to corresponding heat release history.

\section{Acknowledgments}

This project is supported by a seed grant for Space Mission Concept Development of National Space Science Center, Chinese Academia of Science and the Key Laboratory for Thermal Science and Power Engineering of Ministry of Education, Tsinghua University, Beijing, China. The authors thank Prof. Zhuyin Ren and Mr. Qing Xie for their assistance with the numerical simulations, and Prof. Remy Mevel for the discussion of chemical kinetic models. They are also affiliated with the Center of Combustion Energy, Tsinghua University.

\section{Nomenclature}




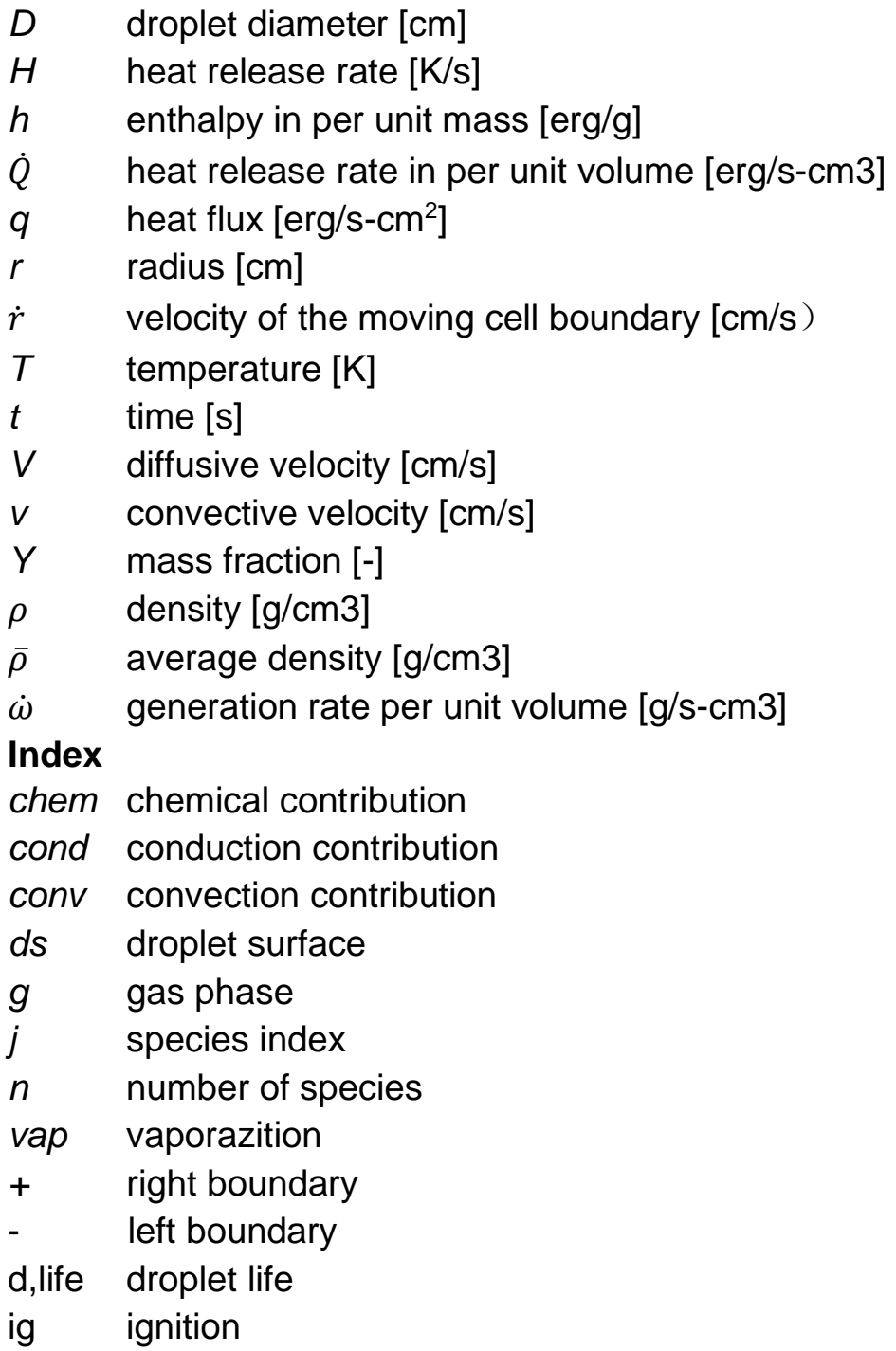

\section{References}

You may use "ASME" citation style in Endnote.

[1] Kumagai S., Sakai T., Okajima S., 1956, Jet Propulsion, 9(26), pp. 786-790.

[2] Tanabe M., Kono M., Sato J., 1994, Twenty-Fifth Symposium (International) on Combustion, 25(1), pp. 455-461.

[3] Tanabe M., Kono M., Sato J., Koenig J., Eigenbrod C., Dinkelacker F., Rath H. J., 1995, Combustion Science and Technology, 108(1-3), pp. 103-119.

[4] Tanabe M., Bolik T., Eigenbrod C., Rath H. J., 1996, Twenty-Sixth Symposium (International) on Combustion, pp. 1637-1643.

[5] Eigenbrod, C., Klinkov, K., Peters, M., Marks, G., Paa, W., Wagner, V., Triebel, W., 2016, Int. J. Microgravity Sci. Appl. 33 330306-1-8

[6] Dietrich D. L., Haggard J. B., Dryer F. L., Nayagam V., Shaw B. D., Williams F. A., 1996, Twenty-Sixth Symposium (International) on Combustion, pp. 1201-1207

[7] Shaw B. D., Clark B. D., Wang D., 2001, AIAA Journal, pp. 2327-2335.

[8] Cuoci A., Frassoldati A., Faravelli T., Ranzi E., 2015, Proceedings of the Combustion Institute, 35, pp. 1621-1627.

[9] Dietrich D. L., 2013, Technical Publication NASA/TP-2013-216046 (2013) NASA, Glenn Research Center, Cleveland $\mathrm{OH} 44135$.

[10] Liu Y., Xu Y., Hicks M., Avedisian C.T., 2016, Combustion and Flame, 171, pp. 27-41. 
[11] Xu Y., Farouk T., Hicks M., Avedisian C.T., 2020, Combustion and Flame, 220, pp. 8291.

[12] Moriuea O., Mikami M., Kojima N., Eigenbrod C., 2005, Proceedings of the Combustion Institute 30, pp. 1973-1980.

[13] Farouk T., Dryer F.L, 2011, Combustion Theory and Modelling, 15(4), pp. 487-515.

[14] Strang G., 1968, SIAM Journal on Numerical Analysis, 5(3), pp. 506-517.

[15] Brown P.N., Byrne G.D., Hindmarsh A.C., 1989, Society for Industrial and Applied Mathematics, 10(5), pp. 1038-1051.

[16] Yoo C.S., Lu T., Chen J.H., Law C.K., 2011, Combustion and Flame, 158, pp. 1727-1741.

Subject area: Fuel sprays \& Combustion

\section{*Corresponding Author:}

Yu Cheng Liu

Center for Combustion Energy, Tsinghua University

Beijing, China, 100084.

Tel.: +86 010-62786707

Email: ycliu7@tsinghua.edu.cn 